\title{
Tipologias de representación social del monte y el sector forestal gallego mediante la construcción de indices
}

\author{
Xesús A. Lage Picos \\ Facultad de Ciencias Sociales y de la Comunicación \\ Universidad de Vigo \\ xalp@uvigo.es
}

\section{INTRODUCCIÓN}

Habitualmente en investigación, la operacionalización de conceptos es una de las etapas cognitivas conformadoras de los procesos de tipo deductivos que preceden al diseño de la observación u obtención de datos 1 . Sin embargo, lo que este artículo propone ilustrar es la operación inversa: el empleo de la operacionalización conceptual para reutilizar datos experimentales procedentes de encuesta. Es decir, siguiendo la lógica inductiva, se pretende mostrar cómo generar conceptos, variables, indicadores e índices, a partir de datos empíricos.

Los datos utilizados proceden de una encuesta de opinión, la Encuesta de Cultura Forestal de Galicia (ECF, 1991) ${ }^{2}$. El bagaje empírico que aporta esta encues-

1 Mediante la operacionalización se trata de concretar hipotesis derivadas de teorías o experiencias en conceptos que puedan ser sometidos a medición, a través del empleo de indicadores. El objeto de este proceder es validar aquello que la teoría o la experiencia trata de predecir. Véase por ejemplo, Boudon, R.; Lazarsfeld, P. (1979): Metodología de las Ciencias Sociales. I. Conceptos e Indices, Barcelona, Edit. Laia, en especial el artículo de Lazarsfeld: «De los conceptos a los índices empíricos», pp. 36-46.

2 Esta encuesta formó parte de las técnicas de análisis empleadas en el estudio de Bases para la elaboración de un plan de divulgación de la cultura forestal, realizado para la Dirección Xeral de Montes e Medio Ambiente Natural, de la Consellería de Agricultura, Gandería e Montes, de la Administración Autonómica Gallega, 1992. Ficha Técnica: 2.570 entrevistas realizadas sobre el universo de personas de más de 18 años residentes en Galicia, en mayo de 1991. Nivel de confianza del $95,5 \%, p=q=50$ y error del 1,97 . Administración del cuestionario mediante entrevistas personal en el hogar. Muestreo mixto que partio de un muestreo por conglomerados, asignando en principio a cada estrato y conglomerado su peso real, y desproporcionándolo posteriormente para que las unidades más pequeñas tuvieran una mínima base de análisis. Selección de los hogares mediante el método Random - Route y del entrevistado por el método Kish. La muestra se estratificó aten- 
ta se inserta en un ámbito de amplio alcance, el de las nuevas formas de representación del monte en un momento en que la relación social con estos entornos ambientales está sometida a una profunda revisión.

El monte forma parte de la realidad social, no es algo externo al que se somete lo social, ni algo que lo social ha de dominar; el monte es un hecho social porque la sociedad realiza del mismo representaciones que guían nuestras percepciones, actitudes, opiniones, y comportamientos, colaborando en la construcción de una imagen social efectiva, tan objetiva como la dimensión física de sus usos. Las representaciones sociales del monte como toda representación social «no sólo inciden en la visión de la realidad social, sino también en su construcción efectiva», son a un tiempo proceso y producto. (Ibañez Gracia, T., 1988: 53-65).

En lo que sigue se da cuenta de la construcción de conceptos y tipologías de interpretación de imágenes del monte, el bosque y el sector forestal, que colaboraron (en buena medida siguen haciéndolo) a orientar discursos y relaciones sociales, en los procesos de elaboración de objetivos de producción para el monte gallego. Además, complementando la operacionalización de los datos empíricos, se realiza un análisis multivariante de interdependencia con la intención de determinar cuáles son las variables que mejor explican las tipologías construidas, y quiénes son los colectivos poblacionales que las respaldan.

\section{LA CONSTRUCCIÓN DE TIPOLOGÍAS DE INTERPRETACIÓN DE LAS REPRESENTACIONES DEL MONTE Y EL SECTOR FORESTAL}

$\mathrm{Al}$ otorgar un alto valor a las funciones ambientales, sociales, y económicas del monte ${ }^{3}$, y expresar el deseo de compatibilizar sus usos ${ }^{4}$, los gallegos de comienzos de los noventa, informaron que compartían referentes y orientaciones culturales comunes. Sin embargo, existían muchas otras cuestiones que hacían sospechar de diferentes grados de adhesión a esos contenidos culturales comunes e incluso de perspectivas opuestas.

Teoricamente, las categorías que en determinadas cuestiones concretan posiciones dispares pueden ser agrupadas para utilizarlas como indicadores de las dimensiones de conceptos, que ayuden a interpretar la estructura de un determinado sistema de opiniones, creencias y actitudes de una población ${ }^{5}$.

diendo a las provincias, al hábitat en cuatro estratos diferenciados, según la altura $(<400$ metros, $>400$ metros), zona eucaliptal o no zona eucaliptal y por zonas piloto de incendios. La encuesta fue realizada por Alef - Millward Brown y Sesfor.

3 Nueve de cada diez entrevistados en la ECF (1991), confirmó que las funciones ambiental $(94,4 \%)$, social $(88,7 \%)$, y económica $(92,6 \%)$ del monte eran muy/bastante importantes.

4 Tres cuartas partes de los gallegos $(76,9 \%)$ creían en que las tres funciones son «perfectamente compatibles», ECF (1991).

${ }^{5}$ López Pintor, R., (1986), «El análisis de los datos de encuesta», en Garcta Ferrando, M.; IbaÑez, J.; AlviRa, F.: El análisis de la realidad social. Métodos y técnicas de investigación, Madrid, Alianza Editorial, 5. a reimpresión, 1993, p. 370. 
Siguiendo esta idea, con las respuestas obtenidas en la ECF se pensó elaborar tipologías de interpretación de los discursos e imágenes que colaboran a orientar las relaciones sociales en los procesos de construcción de la cultura forestal gallega.

A partir del conocimiento empírico que proporcionó el análisis de los marginales de la ECF, y tomando como referentes teóricos la estructura de los sistemas colectivos de creencias elaborado por Inglehart (1991), las propuesta de Mormont (1987) y Halfacree (1993) de lectura de la ruralidad desde la teoría de las representaciones sociales, y la interpretación cultural de la naturaleza de Macnaghten \&Urry (1998), se pensó en delimitar conceptos para interpretar y explicar el campo de las representaciones del monte y la cultura forestal.

Un primer concepto acotado es el de perspectiva representacional, con él se alude a los elementos valorativos y a los razonamientos logicos e ideológicos, utilizados para guiar la construcción de las representaciones del monte, los bosques y el sector forestal. Es decir, la perspectiva representacional se vincula básicamente con una función de interpretación de la realidad, una de las tres funciones que Jodelet (1986: 486) atribuye a las representaciones sociales. Especificando este concepto se distinguen dos dimensiones hipotéticas:

- Dimensión productivista; daría cuenta de las interpretaciones que contribuyen a resaltar la representación del monte y los bosques como un espacios eminentemente productivos, otorgando al sector forestal un papel instrumental en la consecución de esa imagen. Esta dimensión enfatiza el valor de uso físico y está en línea con las ideas de la modernización, para las que el monte y los bosques representan recursos naturales que deben ser explotados y transformados.

- Dimensión postmaterial; hace hincapié en interpretaciones del monte y los bosques que anteponen su simbología a las referencias físicas, recreando imágenes alegóricas que combinan la preservación de los equilibrios ecológicos con su disfrute. Es una dimensión crítica con los tradicionales modos de gestión productiva y de distribución de los recursos, intensamente identificados con el sector forestal, que se sirve de la imagen simbólica recreada para expresar el deseo de un nuevo orden social ${ }^{6}$.

Un segundo concepto delimitado es el de evaluación competencial, con él se nombra la atribución social de responsabilidades en asuntos implicados con decisiones o actividades relacionadas con el monte y los bosques. El concepto remite al juicio de conductas de intervención social hacia los objetos de representación, construidos a través de las perspectivas representacionales.

${ }^{6}$ Como formula Marc Mormont refiriéndose a la redefinición social de la ruralidad: «Rurality is claimed not only as a space to be appropriated for a particular form of leisure or for conservation but as a way of life, or a model of an alternative society inspiring a social proyect that challenges contemporary social and economic ill». MORMONT, M. (1987), «Rural nature and urban natures", en Sociologia Ruralis, n. ${ }^{\circ} 27$, p. 18. 
Por tanto, la evaluación competencial presupone la existencia de una representación social determinada que es la que provoca y condiciona la toma de postura ${ }^{7}$. Al igual que en el concepto anterior pueden precisarse dos dimensiones hipotéticas:

- Dimensión proteccionista; subscribe aquellas posiciones que sostienen la pertinencia de intervenir sobre el monte y los bosques, de regular su gestión, limitando los derechos de propiedad y accesibilidad, supuestamente en nombre del interés público y por mediación del Estado.

- Dimensión liberal; en línea con el precepto clásico del «laisser faire», avala los puntos de vista que respaldan la libertad de los individuos, sean propietarios o usuarios, para disponer de las superficies de monte y bosque, manifestando una clara oposición a orientar o tutelar un determinado tipo de desarrollo.

Delimitados los conceptos se seleccionaron una serie de variables empíricas extraídas de opiniones expresadas en la ECF (ver el anexo metodológico del final del artículo). Estas variables agrupadas convenientemente permiten su consideración como indicadores de las interpretaciones y posiciones definidas respecto a la cultura forestal ${ }^{8}$.

Ponderando o asignado pesos a cada categoría de las variables nominales escogidas se obtienen unos índices y unas escalas de frecuencias, que representan numéricamente las dimensiones de los conceptos o variables genéricas, de perspectiva representacional y evaluación competencial (ver el anexo metodológico del final del artículo).

7 Las orientaciones evaluativas condensan y estructuran los aspectos emocionales de una representación social -responsable última de otorgar significado a un estímulo-, contribuyendo a la función dinámica que determina el tipo de respuestas ante el objeto representado. Ver IBAÑEz GraCia, T. (1988), «Representaciones sociales, teoría y método», en IBAN̂EZ Gracia, T. (Coor.), Ideologias de la vida cotidiana, l'Hospitalet de Llobregat (Barcelona), Sendai ediciones, pp. 13-90.

8 Inicialmente, el número de variables seleccionadas como indicadores para las dimensiones de los dos conceptos construidos era más amplio de las que finalmente se emplearon. Ello se debió a las progresivas pruebas, ajustes y críticas, a las que se sometío a indicadores e índices, hasta que se consideró que los elegidos eran los que mejor reflejaban la realidad subsumida bajo los conceptos utilizados. Véase GonzAlez BlasCo, P., (1989): «Medir en las ciencias sociales». En GaRCia Ferrando, M., et al. (comps.): El análisis de la realidad social, Madrid, Alianza Editorial, pp. 227-286. 
TIPOLOGfAS DE REPRESENTACIÓN SOCIAL DEL MONTE Y EL SECTOR FORESTAL...

TABLA I

Frecuencias de la perspectiva representacional

\begin{tabular}{cccc}
\hline Valor & Frecuencia & Porcentaje & Porcent. Acumulado \\
\hline-7 & 2 & 0,1 & 0,1 \\
-6 & 19 & 0,7 & 0,8 \\
-5 & 25 & 1,0 & 1,8 \\
-4 & 47 & 1,8 & 3,6 \\
-3 & 126 & 4,9 & 8,5 \\
-2 & 176 & 6,9 & 15,4 \\
-1 & 258 & 10,0 & 25,4 \\
\hline 0 & 312 & 12,1 & 37,5 \\
\hline 1 & 357 & 13,9 & 51,4 \\
2 & 382 & 14,9 & 66,3 \\
3 & 300 & 11,7 & 77,9 \\
4 & 232 & 9,0 & 87,0 \\
5 & 201 & 7,8 & 94,8 \\
6 & 97 & 3,8 & 98,6 \\
7 & 36 & 1,4 & 100,00 \\
\hline Total & 2570 & 100,00 & \\
\hline Media 1,3098 & Mediana 1.0000 & Moda 2,00 & Desv. Típ. 2,6799 \\
Varianza 7,1819 & Curtosis -0,356 & & \\
\hline
\end{tabular}

GrÁFICO I

Clasificación de la población gallega en el índice de la perspectiva representacional

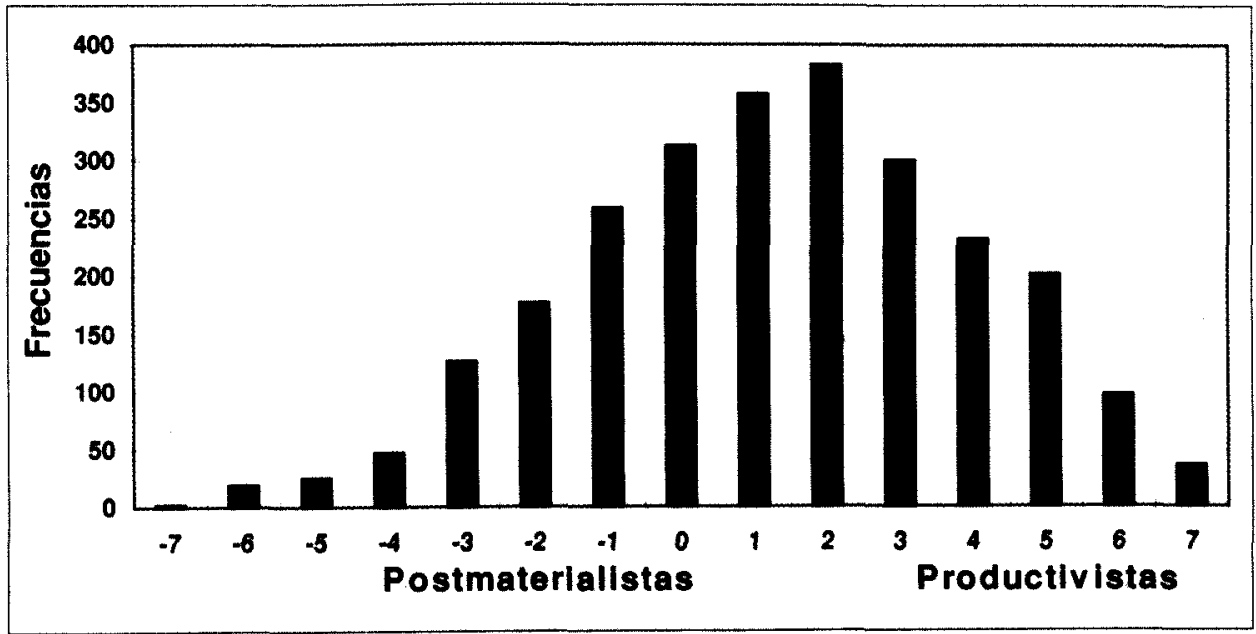

De acuerdo con la distribución de frecuencias de la perspectiva representacional, aquellos entrevistados cuyas opiniones ponderadas alcanzan valores comprendidos entre uno y siete, son considerados como productivistas. Postma- 
terialista son aquellos que obtienen valores ponderados entre menos uno y menos siete. Entre ambos tipos de sujetos, con puntuaciones de cero, se sitúan los que no responden o tienen valores mixtos que se equilibran.

TABLA II

Frecuencias de la evaluación competencial

\begin{tabular}{cccc}
\hline Valor & Frecuencia & Porcentaje & Porcent. Acumulado \\
\hline-8 & 6 & 0,2 & 0,2 \\
-7 & 21 & 0,8 & 1,1 \\
-6 & 20 & 0,8 & 1,6 \\
-5 & 47 & 1,8 & 3,7 \\
-4 & 141 & 5,5 & 9,2 \\
-3 & 149 & 5,8 & 14,9 \\
-2 & 211 & 8,2 & 23,1 \\
-1 & 290 & 11,3 & 34,4 \\
\hline 0 & 502 & 19,5 & 54,0 \\
\hline 1 & 319 & 12,4 & 66,4 \\
2 & 299 & 11,6 & 78,0 \\
3 & 261 & 10,1 & 88,1 \\
4 & 184 & 7,1 & 95,3 \\
5 & 70 & 2,7 & 98,0 \\
6 & 24 & 0,9 & 98,9 \\
7 & 13 & 0,5 & 99,5 \\
8 & 14 & 0,5 & 100,00 \\
\hline Total & 2570 & 100,00 & \\
\hline Media 0,3332 & Mediana 0.0000 & Moda 0,00 & Desv. Típ. 2,6995 \\
Varianza 7,2871 & Curtosis 0,066 & & \\
\hline
\end{tabular}

GrÁFICO 2

Clasificación de la población gallega en el índice de evaluación competencial

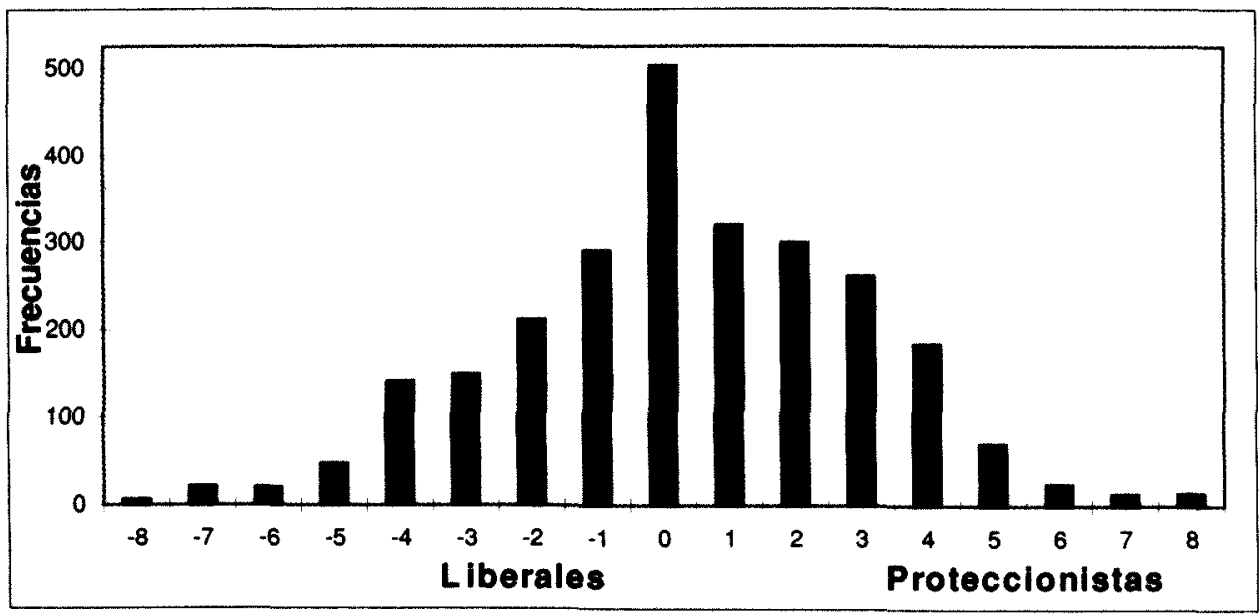


En el índice de evaluación competencial a los entrevistados cuyas opiniones ponderadas alcanzan valores comprendidos entre uno y ocho se les considera como proteccionistas. Los liberales son aquellos que obtienen valores ponderados entre menos uno y menos ocho. Y con puntuaciones de cero quedan clasificados los que no responden y aquellos con juicios dispares que quedan equilibrados.

\section{PRIORIDADES VALORATIVAS Y DISCURSOS DE REPRESENTACIÓN DEL MONTE, LOS BOSQUES Y EL SECTOR FORESTAL}

Elaborados los índices, y clasificada la población que respondió a la encuesta conforme a las puntuaciones asignadas a sus contestaciones, ha de interpretarse la nueva información generada. Comenzando por el índice construido para expresar numéricamente la intensidad de la perspectiva representacional, se observa el mayor peso de valores y discursos productivistas entre la población gallega de comienzos de los noventa.

Seis de cada diez gallegos (63\%) se autoubican entre los que interpretan el monte y los bosques como un espacio de recursos naturales, rentable económicamente para los industriales de la madera, cuya actividad se entiende supone trabajo, desarrollo y riqueza del país. En consonancia con esa lectura, subscriben la idea de que las especies de rápido crecimiento favorece el aprovechamiento del monte, y que la actividad de los industriales determina su cuidado y proliferación. Así mismo, se muestran reticentes a pagar por áreas de recreo bien cuidadas, $y$ creen en que es prioritario intensificar la producción de madera sobre cualquier otra alternativa, para satisfacer el creciente consumo de sus productos derivados.

Un reducido grupo lo componen los que no poseen una clara posición definida $(12 \%)$. El cuarto restante son postmaterialistas $(25 \%)$, es decir, aquellos que recomponen una visión representacional del monte y los bosques, amenazada por la actividad especulativa de unos industriales de la madera con los que se vincula su deterioro. Talas, incendios, degradación ambiental, son las ideas que se asocian a la gestión productiva de la madera. Con acuerdo a ello, las especies de rápido crecimiento no son dignas de su consideración, se muestran dispuestos a pagar por áreas de recreo bien cuidadas, y dan prioridad al reciclaje sobre cualquier otra medida alternativa que satisfaga el consumo de bienes elaborados a partir de la madera. Conservación y recreo frente a producciones tangibles, resumen sus propuestas de reedificación del monte y los bosques gallegos.

Las características sociales que informan de variaciones relevantes en el peso de las categorías tipológicas de la perspectiva representacional son: la edad, el hábitat, el nivel de estudios, la situación laboral y la vinculación con la propiedad forestal ${ }^{9}$.

${ }^{9}$ En todas las categoría de estas variables independientes los productivistas son mayoría, pero aumentan su proporción significativamente las siguientes: los adultos ( $>$ de 55 ańos\%; productivistas, $70,6 \%$ ), los núcleos rurales de menor población (parroquias y aldeas de municipios de 
El índice de la perspectiva representacional parece avalar la idea de una polarización incipiente de la población gallega en torno a dos formas de concebir el monte y el sector forestal. Una situación marcada por las diferentes experiencias generacionales respecto al proceso de cambio histórico, en el que la sociedad gallega se encuentra inmersa.

De una parte, en consonancia con su reciente pasado agrario, la sociedad gallega continúa asociando en gran medida el monte a usos productivos con los que satisfacer mayores cotas de bienestar material y crecimiento económico. A la prevalencia de lecturas productivistas de las generaciones de los más adultos, socializados en una sociedad agraria tradicional (preindustrial), se aúna el deseo de las generaciones de mediana edad (protagonistas de la mercantilización y el despegue industrial de la sociedad gallega), de profundizar en el paradigma de la transformación de las condiciones económicas precedentes, mediante el uso de la modernización productiva.

De otra, las lecturas menos marcadamente productivistas o incipientemente postmaterialistas de: los jóvenes, residentes en ciudades, con estudios superiores, profesionales, funcionarios o estudiantes, y que no son propietarios de montes. Entre estos sectores de población gallega, el monte comienza a ser concebido como espacio simbólico de consumos postproductivos. Su ubicación ideológica se muestra crítica con el desarrollo modernizador del monte, y son especialmente sensibles a los problemas de degradación ambiental. Marcan diferencias con respecto a los modos de gestión productiva utilizados, argumentando en contra de las especies de crecimiento rápido y de la actividad de los industriales de la madera. Monte y bosques se integran como espacios en los que recrear estilos de vida característicamente postmateriales.

En la tipología de evaluación competencial, el índice elaborado advierte del predominio de los proteccionistas (46\%), sobre liberales (34\%), y sobre los que no tienen una posición muy clara $(20 \%)$.

A partir de su particular representación del monte, los proteccionistas creen que el monte y los bosques deben ser intervenidos, mostrándose por tanto en desacuerdo con no tocar un monte reconocidamente deteriorado ${ }^{10}$. Reclaman limitar los derechos de propiedad, controlar el acceso público y regular el tipo de árboles que se ha de plantar.

El contrapunto de los proteccionistas son los liberales, que expresan juicios reticentes a la intromisión en decisiones o cuidados, que limiten la competencia

menos de 10.000 habitantes; $70,1 \%)$, los que poseen un nivel de estudios bajo $(69,4 \%)$, agricultores $(72,7 \%)$, empresarios (propietarios de industrias o comercios; $69,9 \%$ ), jubilados $(72,2 \%)$, y propietarios de monte que realiza algún tipo de aprovechamiento de su monte $(73,9 \%)$. De este modo, el resto de las categoría de esas variables independientes aumentan la proporción del $25 \%$ de postmaterialistas, especialmente: los jóvenes de $18-24$ años $(33,9 \%)$, los residentes en las ciudades gallegas (siete núcleos $>50.000$ habitantes) $(30,9 \%)$, los que poseen estudios superiores $(34,9 \%)$, profesionales $(34,1 \%)$, funcionarios $(39,7 \%)$, estudiantes $(42,9 \%)$, y entre los que no son propietarios de monte $(28 \%)$.

${ }_{10}$ Los gallegos habían informado de un importante deterioro, tanto de los montes de su zona de residencia (P. 8: «bastante o muy deteriorados», 74, 3\%), como de los montes gallegos en general (P. 7: «bastante o muy deteriorados», 83,9\%), ECF (1991). 
de la propiedad privada sobre sus montes y restrinjan su accesibilidad. Se muestran remisos ante el voluntarismo, lo que les lleva a respaldar la idea de no tocar el monte. Reclaman el derecho de los propietarios a hacer con sus tierras lo que más les convenga, y a transitar sin control por los bosques, negándose a la necesidad de regular que tipo de árboles se han de plantar.

El hábitat, el nivel de estudios, la situación laboral y la vinculación con la propiedad forestal, son características que registran alteraciones en el peso de las categorías tipológicas de la evaluación competencial ${ }^{11}$.

El predominio de los proteccionistas se relaciona con dos circunstancias principales: con la precariedad de los conocimientos culturales relacionados con el monte y los bosques, y con la falta de cultura política y organizativa.

El creciente olvido de la memoria histórica del pasado agrario, facilita que la población gallega pierda el referente cultural del papel que desempeñó el monte en una sociedad agraria de subsistencia. Con el paso del tiempo el monte fue progresivamente relegado, se abandonaron los modos de gestión tradicionales y muchos de sus aprovechamientos. El cambio generacional, acompañado de la terciarización de la economía, y de la redistribución de los asentamientos en torno a las ciudades y lugares centrales con algún tipo de funcionalidad ${ }^{12}$ (villas y cabeceras comarcales), se conjugan dilatando las distancias referenciales.

Ciertamente, la propiedad y la administración forestal han tenido un protagonismo importante en el aumento de las superficies arboladas, pero la cultura selvícola -entendida como cuerpo de conocimientos técnicos, relacionado con el cuidado del monte y los bosques- no llegó a propagarse entre los propietarios, y mucho menos entre el resto de la población ${ }^{13}$.

Por otro lado, el proteccionismo también se relaciona con la endeble cultura política y organizativa, en la que han crecido la mayoría de los gallegos.

Históricamente, las redes de poder local han colaborado con formas de administración del poder y de resolución de problemas sociales, que alimentan el paternalismo y la dependencia clientelar. Esto facilita la intervención de los poderes públicos, antes que la negociación de metas sociales y la participación en la gestión de problemas.

1 Así, invierten o equiparan el peso de las posiciones extremas: los núcleos municipales inferiores a 10.000 habitantes (liberales, $40 \%$; proteccionistas, $39 \%$ ) y las parroquias y aldeas del estrato anterior (liberales, $46 \%$; proteccionistas, $36 \%$ ), los que no poseen estudios (liberales, $43 \%$; proteccionistas, $41 \%$ ), agricultores (liberales, $45 \%$; proteccionistas, $34 \%$ ), empresarios (liberales, $40 \%$; proteccionistas, $40 \%$ ), jubilados (liberales, $39 \%$; proteccionistas, $42 \%$ ), y propietarios que realizan algún tipo de aprovechamiento de sus propiedades de monte (liberales, $43 \%$; proteccionistas, 35\%).

12 Precedo Ledo, A. (1994), Desenvolvemento Territorial e Planificación Comarcal, Santiago de Compostela, Gabinete de Planificación e Desenvolvemento Territorial, Consell. de Presidencia, Xunta de Galicia, p. 101.

13 Un par de indicadores de la carencia de conocimientos selvícolas, suministrados por las opiniones de la población, son el acuerdo que suscita la idea de que: «Se tiene poca información sobre los árboles más idóneos para repoblar» (P. 72: «muy o bastante de acuerdo», 88,6\%), y el suspenso en el nivel de conocimientos sobre el bosque que recibe la población urbana (P. 59: «mucho o bastante conocimiento», $27,5 \%$ ). 
Los movimientos sociales, por su parte, han alimentado también, la cultura de resolución de problemas desde la reivindicación de la presencia del interés público ${ }^{14}$, una característica compartida con otras sociedades occidentales en el tratamiento de los problemas asociados a la revalorización de los recursos naturales como patrimonio colectivo ${ }^{15}$.

Junto a una cultura política, cautiva de su pasado y de la reivindicación, las carencias de la cultura organizativa también favorecen el proteccionismo ${ }^{16}$. El bloqueo del desarrollo organizativo impide articular respuestas «técnicamente correctas, económicamente viables y socialmente aceptadas» ${ }^{17}$, lo que facilita aún más, la delegación y la mediación del Estado en los temas implicados con decisiones o actividades relacionadas con el monte y los bosques.

Por su parte, los liberales (recuérdese, el $34 \%$ de la población), aunque rechacen delegar atribuciones, tampoco parecen haber contribuido mucho a mejorar los modos de gestión del monte y los bosques. A ellos se hacen extensibles las carencias técnicas, políticas y organizativas, citadas con anterioridad.

Los liberales traducen un rechazo inhibidor y obstruccionista a la acción de las instituciones y redes de poder que tradicionalmente han sido las responsables de la modernización, pero su capacidad como colectivo para articular respuestas no ha conseguido frenar la postergación del monte y los bosques. La defensa de la propiedad impide contemplar, con frecuencia, el establecimiento de unidades de monte con una escala apropiada para diseñar objetivos que concilien intereses y solventen los problemas de su manejo.

El índice de evaluación competencial posee un alto nivel de concentración en posiciones intermedias (en el grupo mixto, un $20 \%$ de la población, se encuentra la moda) ${ }^{18}$. En este caso se combinan distintas alternativas a la hora de la

14 «La importancia pública atribuida al bosque deriva de su creciente concepción como un patrimonio colectivo al que están estrechamente asociadas nuestra supervivencia y calidad de vida, tal como subrayaron recientemente el X Congreso Forestal Mundial de París (Octubre, 1991) y la Conferencia sobre Medio Ambiente de Río de Janeiro (Junio, 1992). ...», Pérez Vilariño, J. (1993), «Organización y Cultura Forestal», en Actualidad Forestal de Galicia, Suplemento de la Revista El Campo, BBV, números 127-130, p. 47.

15 Marc Mormont refiriéndose a las representaciones de los parques naturales, comenta que uno de sus elementos comunes es el recurso a vincular al Estado en su promoción y defensa. «These two views ... have come to consider regional nature parks to be a form of management with the State as either the promoter or the guarantor-responding to the need for redeployment of these areas, and thus to the need for a total or partial redeployment of various strata of their inhabitants. ...", MORMONT, M. (1987), op. cit., p. 4.

${ }_{16}$ «El punto organizativo más débil que presenta el sector forestal son los silvicultores. Su organización constituye la condición indispensable para poder negociar con algún peso, tanto con las administraciones públicas que desconocen incluso su número como con los grandes grupos industriales. ... El éxito logrado por el sector forestal en los paises de Norte de Europa está, sin duda, asociado al alto grado de integración organizativa de las empresas de transformación y de las asociaciones de propietarios, estimulado por una administración pública que asume su doble papel de arbitraje y de promoción política. ...». PÉREZ VILARINO, J (1998), «Construcción social del monte y desarrollo corporado del sector forestal», en Agricultura y Sociedad, n. ${ }^{\circ} 85$, p. 33 y 34.

17 Ibíd., p. 25.

18 La distribución es unimodal, ligeramente asimétrica negativa y leptocúrtica (ver gráfico 2), es decir los valores del índice de evaluación competencial apuntan la distribución. Los valores del índice comprendidos entre -2 y +2 representan el $63 \%$ de la población. 
atribución social de responsabilidades en asuntos relacionados con el monte y el sector forestal, recortando fuerza a las posiciones extremas de la escala.

Proteccionismo y liberalismo se encuentran muy entreverados entre la población, lo que expresa una voluntad implícita de compartir atribuciones. Se solicita la intervención de los poderes públicos, tanto como de la participación personal en la definición de objetivos y métodos de gestión del monte y los bosques, aunque la distribución asimétrica negativa otorgue un mayor peso a los proteccionistas que a los liberales.

Con respecto a ésta, la distribución de las frecuencias del índice de la perspectiva representacional ${ }^{19}$, hace valer con autoridad el predominio de las visiones productivistas, sobre las incipientes representaciones postmateriales.

\section{ANÁLISIS DE SEGMENTACIÓN DE LAS TIPOLOGÍAS}

En el apartado precedente, se ha podido ver que existen una serie de variables independientes (edad, hábitat, nivel de estudios, situación laboral y vinculación con la propiedad), que introducen variaciones relevantes en la forma de representar y atribuir potestad en las cuestiones referidas con el monte y el sector forestal. Profundizando en el análisis, se puede intentar determinar cuáles de esas variables independientes explican mejor las tipologías construidas. Para adentrarnos en esta indagación, se somete a las variables nominales generadas a un análisis de segmentación ${ }^{20}$.

Las variables que deseamos explicar son las variables genéricas perspectiva representacional y de la evaluación competencial, y los pronosticadores que se utilizan son todos los que demostraron provocar variaciones en las mismas (edad, hábitat, nivel de estudios, situación laboral y vinculación con la propiedad), a los que añadiremos la zona altimétrica y el sexo, para obtener confirmación que las otras variables son más relevantes.

De los procedimientos para realizar la segmentación, se utilizo el algoritmo CHAID ${ }^{21}$ que permite «formar segmentos con más de dos categorías al unísono» (Escobar, 1998: 18).

19 La distribución de las frecuencias del índice de la perspectiva representacional es mucho más marcadamente asimétrica negativa (ver grafico 1). La mediana 1,00, y moda 2,00, son de signo positivo y están separadas por una unidad, mientras que en la distribución del índice de evaluación competencial, la moda y la mediana coinciden en 0 .

20 «Segmentar significa dividir y este análisis permite con su algoritmo el hallazgo de grupos muy distintos en una determinado aspecto. Por tanto, uno de los usos que se le puede dar a la segmentación es la descripción de las muestras y, por extensión, de las poblaciones de las que son extraídas». EsCOBAR, M. (1998), «Las aplicaciones del análisis de segmentación: El procedimiento Chaid», en EMPIRIA, n. ${ }^{\circ} 1$, p. 40 . «Es ésta una técnica de dependencia entre variables. En su uso, se distinguen, por una lado, una variable cuya distribución se desea explicar y, por el otro, un conjunto de variables, nominales $u$ ordinales, con estatus de independientes. Éstas reciben el nombre de pronosticadoras y tienen la finalidad de conformar grupos que sean muy distintos entre si en la variable dependiente». Ibíd., p. 13.

21 Se emplea el algoritmo CHAID (Chi-squared Automatic Interaction Detection), y el paquete Answer Tree (versión 1.0), del programa estadístico SPSS. 
GrÁFICO 3

Segmentación perspectiva representacional del monte y el sector forestal en Galicia, 1991

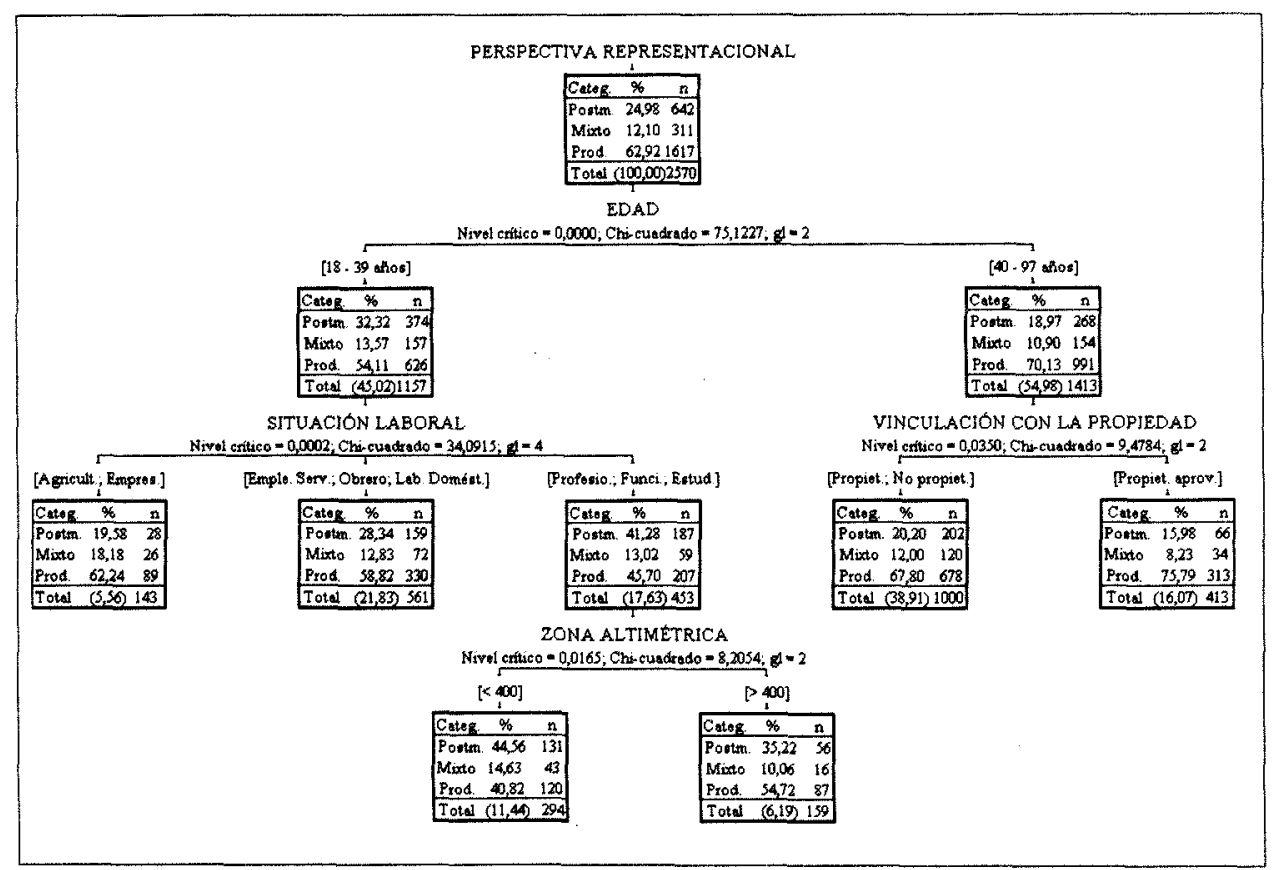

Los resultados de la segmentación de la perspectiva representacional se presentan en el gráfico 3. El gráfico ilustra que son cuatro las variables pronosticadoras, de las siete utilizadas, las que consiguen formar seis grupos terminales. La más relevante es la edad que evidencia una barrera generacional en los cuarenta años. A continuación en función de si se es joven o adulto, la situación laboral y la zona altimétrica en el primer caso, y la vinculación con la propiedad en el segundo, consiguen diferenciar los seis grupos terminales.

La segmentación no consigue establecer grupos muy distintos respecto del modo en que se representa al monte, los bosques y el sector forestal. La perspectiva productivista es mayoritaria sin paliativos entre la población gallega. Ahora bien, aunque la perspectiva productivista sea la categoría modal de cinco de los seis grupos de segmentación terminales, ello no descarta completamente el valor de la segmentación realizada.

La segmentación colabora a describir a la población gallega con respecto a su mayor o menor énfasis productivista, identifica los pronosticadores que mejor lo explican y localiza a un grupo netamente postmaterialista. 
TABLA III

Grupos resultantes de la segmentación de la perspectiva representacional del monte y el sector forestal en Galicia, 1991

\begin{tabular}{lcccc}
\hline Grupos & n & \% Total & \% Product. & \% Postmaterial \\
\hline $\begin{array}{l}\text { 1/ Adultos (40-97), propietarios de } \\
\text { monte que realizan } \\
\text { aprovechamientos. }\end{array}$ & 413 & 16,07 & 75,79 & 15,98 \\
\hline $\begin{array}{l}\text { 2/ Adultos (40-97), propietarios que } \\
\text { no realizan aprovechamientos y } \\
\text { no propietarios de monte. }\end{array}$ & 1000 & 38,91 & 67,80 & 20,20 \\
\hline $\begin{array}{l}\text { 3/ Jovenes (18-39), agricultores o } \\
\text { empresarios. }\end{array}$ & 143 & 5,56 & 62,24 & 19,58 \\
$\begin{array}{l}\text { 4/ J6venes (18-39), empleados de } \\
\text { servicios, obreros y labores domésticas. }\end{array}$ & 561 & 21,83 & 58,82 & 28,34 \\
\hline
\end{tabular}

5/ Jóvenes (18-39), estudiantes,

funcionarios y profesionales, residentes

en el interior.

159

6,19

54,72

35,22

6/ Jóvenes (18-39), estudiantes,

funcionarios y profesionales,

residentes en la franja litoral.

\begin{tabular}{rrrr}
294 & 11,44 & 40,82 & 44,56 \\
\hline 2570 & 100,00 & & \\
\hline
\end{tabular}

Como era de esperar después de la frecuencia con que aparece en el análisis bivariable, la edad es el pronosticador que mejor expresa la perspectiva representacional del monte, los bosques y el sector forestal, avalando la idea de la pertinencia de considerar sensibilidades generacionales distintas en sus interpretaciones: los jóvenes (18-39 años) son más moderados que los adultos (40-97), a la hora de concebir el monte como un espacio eminentemente productivo y suministrador de materias primas.

La moderación con la que los jóvenes otorgan mayor valor subjetivo a las representaciones que vinculan al monte a la modernización productiva, se relacionan con toda probabilidad con un incipiente cambio de valores. Entre las nuevas generaciones de gallegos comienza a definirse un nuevo tipo de carencias en relación a los montes y el sector forestal. Este sector de la población es más sensible a la defensa medio ambiental, a la desigualdad en el reparto de los recursos, y a la necesidad de habilitar nuevos espacios para el ocio, que sus mayores.

A pesar de que las representaciones productivistas son mayoritarias, los adultos reflejan mejor la prevalencia de la prioridad de ligar al monte y al sector forestal, a un desarrollo económico que ya anhelaban en su vida preadulta ${ }^{22}$.

22 Para un examen de la idea del cambio de valores intergeneracional puede verse INGLEHART, R. (1991), El cambio Cultural en las sociedades industriales avanzadas, Madrid, C.I.S., col. monografías n. ${ }^{\circ} 121$. Este autor argumenta como marco térico para el examen de la teoría del cambio de valores las hipotesis de la escasez y de la socialización (p. 61). Por un lado cada generación otor- 
Entre los adultos, la vinculación con la propiedad contribuye a discernir que son los propietarios de monte que afirman realizar algún tipo de aprovechamiento, los más identificados con la perspectiva productivista. La experiencia del uso productivo del monte marca su percepción e interpretación, proporcionando una información de primera mano para estructurar sus representaciones.

Entre los jóvenes, la situación laboral contribuye a matizar la perspectiva representacional, dando lugar a tres grupos. El primero formado por aquellos que tienen una proporción de posmaterialistas próximo al de los adultos, son trabajadores del sector agrario o empresarios. Un segundo grupo, el más numeroso entre los jóvenes $(21,83 \%$ de la población total), trabajadores empleados de servicios, obreros, o dedicados a labores domésticas, donde se percibe una reducción de representaciones productivistas, en favor de las posmaterialistas. Por último, están los estudiantes, profesionales y funcionarios, segmento poblacional donde las representaciones del monte y el sector forestal se encuentran polarizadas, aunque con un ligero predominio de los productivistas.

Se precisa de una nueva variable, la zona altimétrica, para hallar un grupo netamente de posmaterialista. La polarización detectada entre los jóvenes, estudiantes, profesionales y funcionarios, se decanta del lado de los posmaterialistas, cuando estos residen en la franja de costa de Galicia, mientras que en el interior sigue siendo mayoritaria las representaciones productivistas.

Una explicación plausible de porqué son específicamente los jóvenes de la franja de costa, estudiantes, funcionarios o profesionales, los que se apartan de la representación del monte y el sector forestal, más común entre los gallegos, se relaciona con la idea de los estilos de vida.

En tanto que jóvenes de la zona donde la utilización del territorio es más intensiva, tanto urbana como productivamente, lo escaso en su entorno se relaciona con espacios extensivos, entre los que los bosques no ligados a fines productivos poseen un lugar preeminente en su imaginario colectivo. Al mismo tiempo, su situación socio-laboral añade peculiaridades culturales y económicas que los hacen distintos, no ya sólo como es patente en sus valores y actitudes, sino también en sus comportamientos de ocio y de relación social $^{23}$.

ga mayor valor subjetivo a aquellas cosas relativamente escasas en su entorno, por otro, los valores que expresa una generación recogen la prevalencia de aquellas prioridades que estaban presentes en su vida preadulta.

${ }^{23}$ «... Cualquiera que sea su motivación tipo de actividad, estilo de vida o grupo al que pertenezcan o del que vayan acompañados, los individuos que disfrutan del ocio al aire libre, todos ellos encuentran en el entorno ecológico una emoción (que unas veces proviene de la excitación y otras de la simple relajación de tensiones) imposibles de encontrar en la ciudad. El nuevo entorno desarrolla entre ellos nuevas relaciones sociales, nuevas amistades y hasta nuevos grupos sociales en forma de club, de federación o de simple peña de amigos del bos. que. ...», Ruiz Olabuenaga, J.I. (1994), «Ocio y estilos de vida», en JuÁRez, M. (Dir.): V Informe Sociológico sobre la situación social en España. Sociedad para todos en el año 2000 , Madrid, Fundación FOESSA, tomo 2, p. 1949. 
En este segmento de población donde se siente con mucha más intensidad la representación postmaterialista, el monte y los bosques se conciben como entornos ideales, con finalidades que reconstruyen espacios de sociabilidad y de lucha colectiva ${ }^{24}$. Vivencia personal y participación se aúnan, activando la denuncia del orden social establecido; la reclamación de identidades (nacionales, locales, grupales o individuales); la discusión en torno a cómo gestionar los patrimonios colectivos.

El análisis de segmentación de la variable perspectiva representacional descarta la significación de tres pronosticadores, el sexo, el nivel de estudios y el hábitat. En el caso del sexo era previsible porque había sido utilizado como variable de control, pero sorprende que no se hayan empleado los otros dos pronosticadores que informaban de variaciones relevantes en el peso de las categorías de la tipología representacional, mientras que la zona altimétrica, la otra de las variables de control introducidas, resulte relevante.

La observación anterior añade valor al análisis de segmentación realizado. A través del análisis multivariable, se ha podido determinar una jerarquía de significación entre las variables responsables de la tipología, cualitativamente distinta de lo que se deducía del análisis bivariable.

La edad, el pronosticador más relevante, intercepta la significación del hábitat o el nivel de estudios. Al fin y al cabo los jóvenes por formación y trabajo residen en zonas de mayor densidad, y poseen generalmente un historial escolar más dilatado del que tienen los adultos. Por su parte, el parámetro de la zona altimétrica (la altura de >de 400 metros, conjuga hábitats densamente poblados, con la franja de radicación del eucalipto), resulta significativo tan sólo después de que se haya descartado el resto de los pronosticadores. Advierte de que entornos ambientales diferenciados como son el litoral respecto del interior, colaboran en matizar la sensibilidad de los jóvenes, estudiantes, funcionarios o profesionales, respecto a la carencia de espacios naturales y la necesidad de una modernización productiva del monte.

La aplicación del análisis de segmentación a la variable de evaluación competencial se recogen en el gráfico 4. La segmentación de la variable evaluación competencial consigue establecer grupos diferentes respecto a las atribuciones que se registran en la variable dependiente, aunque la mejora en el pronóstico no sea notoria ni decisiva. El tamaño de la categoría mixta (19\% de posiciones intermedias), como se comentó al examinar el gráfico de distribución de frecuencias de la variable, reduce la posibilidad de que los contrastes sean más claros.

${ }^{24}$ LiPOVETSKY, G. (1994), El crepúsculo del deber. La ética indolora de los nuevos tiempos democráticos, Barcelona, Anagrama, Col. Argumentos n. ${ }^{\circ} 148$, pp. 215-221. 
GRÁFICO 4

Segmentación de la evaluación competencial en decisiones o actividades relacionadas con el monte y los bosques. Galicia, 1991

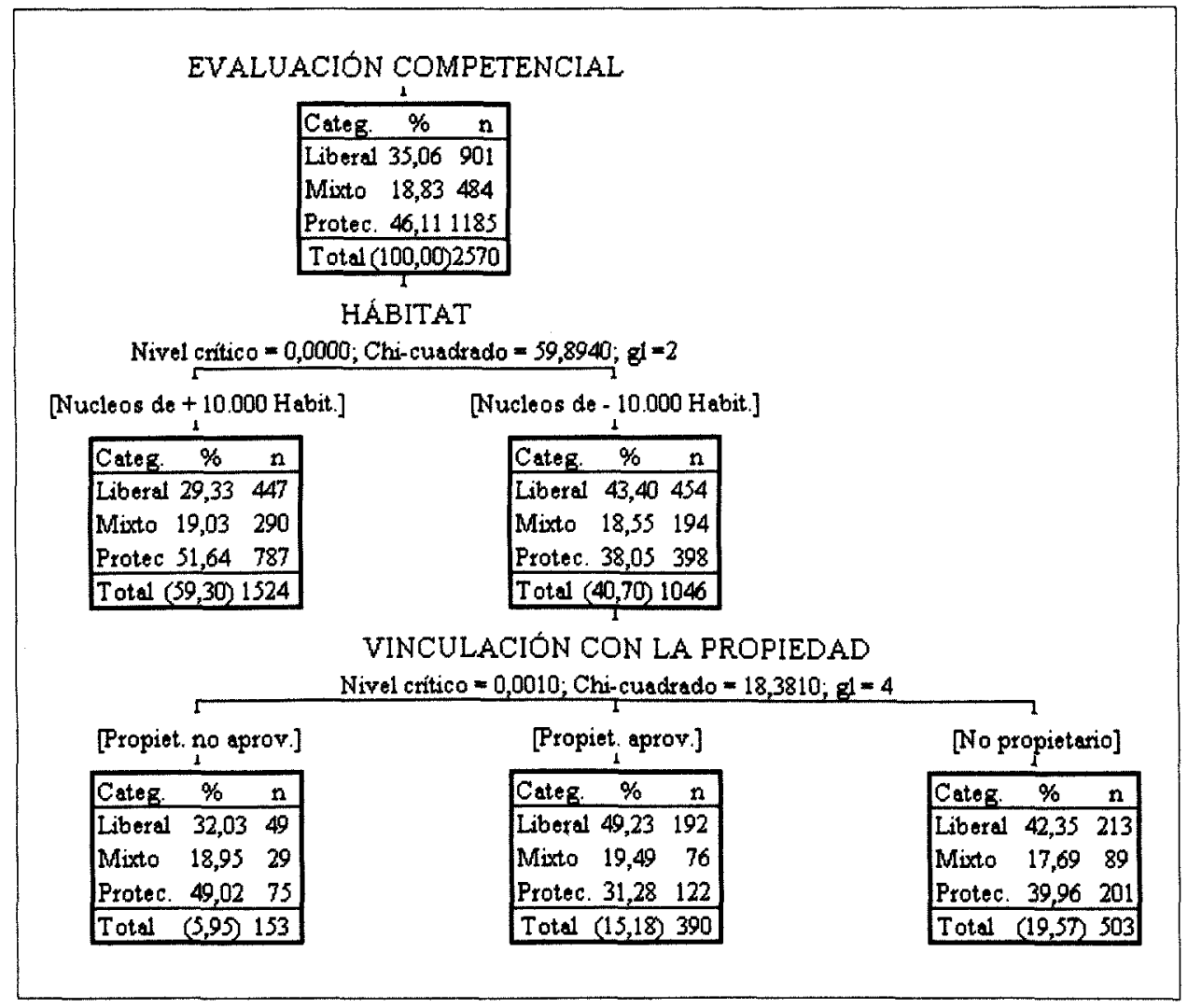

A diferencia que en la anterior tipología, aquí sí que el hábitat resulta altamente significativo, hasta el punto de ser capaz de establecer dos grupos heterogéneos, con posiciones contrarias respecto de la atribución competencial en cuestiones relacionadas con los montes y los bosques gallegos.

Las posiciones de los residentes en los núcleos de mayor entidad de población (entre 10.000 y 50.000 habitantes), los «urbanitas», subscriben el proteccionismo dominante en la variable dependiente y no admite segmentaciones posteriores. Por el contrario, la población rural (residentes en entidades de población de menos de 10.000 habitantes; villas y aldeas), invierte el sentido de las ubicaciones de la variable dependiente, registrando la presencia de más liberales que proteccionistas.

Utilizando como pronosticador la vinculación con la propiedad de monte, el análisis de segmentación, a partir de la población rural, admite diferenciar tres nuevos grupos terminales: el de los propietarios que no sostienen aprovechamiento de su propiedad de monte, un grupo con unas posiciones internas que 
reproducen muy de cerca las de la variable dependiente; los propietarios que realizan aprovechamientos de sus montes, quienes disienten con la intromisión en lo que consideran su dominio; y por último, la población rural que no es propietaria, con posiciones que casi quedan neutralizadas a pesar de que los liberales sean ligeramente superiores a los proteccionistas.

TABLA IV

Grupos resultantes de la segmentación de la evaluación competencial del monte y el bosque gallego, 1991

\begin{tabular}{lcccc}
\hline Grupos & n & \% Total & \% Protecc. & \% Liberal. \\
\hline $\begin{array}{l}\text { 1/ Adultos (40-97), propietarios de } \\
\text { monte que realizan } \\
\text { aprovechamientos. }\end{array}$ & 413 & 16,07 & 75,79 & 15,98 \\
\hline $\begin{array}{l}\text { 1/ Residentes urbanos (>10.000 } \\
\text { habitantes). }\end{array}$ & 1524 & $-59,30$ & 51,64 & 29,33 \\
\hline $\begin{array}{l}\text { 2/ Residentes rurales (<10.000 } \\
\text { habitantes), propietarios que no realizan } \\
\text { aprovechamientos. }\end{array}$ & 153 & 5,95 & 49,02 & 32,03 \\
$\begin{array}{l}\text { 3/ Residentes rurales, no propietarios } \\
\text { de monte. }\end{array}$ & 503 & 19,57 & 39,96 & 42,35 \\
$\begin{array}{l}\text { 4/ Residentes rurales, propietarios que } \\
\text { no realizan aprovechamientos. }\end{array}$ & 390 & 15,18 & 31,28 & 49,23 \\
\hline & 2570 & 100,00 & & \\
\hline
\end{tabular}

Los dos pronosticadores significativos, el hábitat y la vinculación con la propiedad, apuntan en una misma dirección: la distancia con respecto al objeto de representación, determina los juicios de a quién atribuir autoridad para definir objetivos y gestionar el monte y los bosques, una distancia que es más socio-cultural que física o emotiva.

Sólo un pequeño grupo de propietarios que realizan usos productivos -los más próximos física y culturalmente-, se considera competente para fijar objetivos y manejar el monte. El resto de la población, incluidos los propietarios de residencia rural que no realizan aprovechamientos, cada vez más lejos de referentes culturales tradicionales, limitados por la cultura política y organizativa, señalan como prioritaria la intervención y regulación, por encima de la defensa de su libre disponibilidad.

Se hace preclara la delegación y la mediación del Estado en los temas implicados con decisiones o actividades relacionadas con el monte y los bosques. A pesar de que las representaciones predominantes del monte, los bosques y el sector forestal gallego posean un sesgo claramente productivo, existe un reconocimiento expreso de la incapacidad de asumir su gestión.

El monte gallego es más un espacio imaginado que del que se tiene conocimiento. Su vivencia activa posicionamientos valorativos que inciden en su repre- 
sentación como espacio productivo e incipientemente posmaterial, pero la precariedad de la cultura selvícola y de la negociación, demanda el arbitrio de la administración pública.

Si el monte y el sector forestal gallego son capaces de atraer la atención de la población desplazando su relegamiento, nuevos y viejos actores se verán obligados a negociar sus objetivos a pesar de la distancia que pueda existir entre sus perspectivas representacionales, pero sin perder de vista que: «El instrumento obligado de mediación entre la nuevas tecnologías y las nuevas demandas sociales sobre el monte y el sector derivado es el desarrollo y la difusión de una cultura forestal con una sólida base profesional» ${ }^{25}$.

Concluye así un trabajo que comenzó por plantear cómo emplear la operación conceptual con datos empíricos preexistentes. Los contenidos expuestos han trazado los pasos seguidos desde la delimitación teórica de conceptos, hasta completar un análisis multivariable con variables tipológicas.

Las fases del proceso han dado cuenta de la estructura de valores y actitudes de las que se servían los gallegos a comienzos de los noventa, para representar el monte, los bosques y el sector forestal. De este modo se ha podido testar la validez de las predicciones realizadas por los referentes teóricos del cambio de valores y habilidades sociales, en la relación con el entorno ambiental. Con ciertas peculiaridades, la sociedad gallega se ajusta lentamente a las realidades que predicen los modelos empleados, a pesar de la proximidad de su pasado agrario y la debilidad de su cultura política y organizativa.

\section{BIBLIOGRAFÍA}

Bell, Daniel (1994): Las contradicciones culturales del capitalismo, Madrid: Alianza Editorial, e.o. 1976.

- (1991): El advenimiento de la sociedad post-industrial, Madrid: Alianza Universidad, n. ${ }^{\circ} 149,3 .^{a}$ ed. en español, e.o. 1973.

Boudon, R.; Lazarsfeld, P. (1979): Metodología de las Ciencias Sociales. I. Conceptos e Indices, Barcelona: Edit. Laia.

CAMARERo, L. A. (1999): «La transición rural en la Galicia postindustrial», en VV.AA.: Actores Sociais e factores de cambio no medio rural, Servicio Publicacións, U. Vigo, Col. Congresos, pp. 15-32.

Escobar, M. (1998): «Las aplicaciones del análisis de segmentación: El procedimiento Chaid», en EMPIRIA, n. ${ }^{\circ} 1$, pp. 13-49.

García Ferrando, M.; IbÁ̃̃ez, J.; Alvira, F. (1993): El análisis de la realidad social. Métodos y técnicas de investigación, Madrid: Alianza Editorial.

GonzÁlez Blasco, P., (1989): «Medir en las ciencias sociales». En Garcia Ferrando, M., et al. (comps.): El análisis de la realidad social, Madrid: Alianza Editorial, pp. 227-286.

HALFACREE, K.H., (1993): «Locality and social Representation: Space, Discourse and Alternative Definitions of the Rural», Journal of Rural Studies, Vol. 9, n. ${ }^{\circ} 1$, pp. 23 37.

25 Perez Vilariño, J. (1992), «Desarrollo tecnologico y cultura forestal», en Actualidad Forestal de Galicia, suplemento de la Revista El Campo, n. ${ }^{\circ}$ 123-126, enero-diciembre, p. 24 y ss. 
IBÁNEZ GRACIA, T. (Coor.): Ideologías de la vida cotidiana, Barcelona: Sendai ediciones. INGLEHART, R. (1991): El cambio Cultural en las sociedades industriales avanzadas, Madrid: CIS, col. monografías $n .^{\circ} 121$.

JODELET, D. (1986): «La representación social: fenómenos, concepto y teoría», en Moscovici, S. (ed.), Psicología Social, II. Pensamiento y vida social. Psicología Social y problemas sociales, Barcelona: Paidos, pp. 469-494, e.o. 1984.

LiPOVETSKY, G. (1994): El crepusculo del deber. La ética indolora de los nuevos tiempos democráticos, Barcelona: Anagrama, Col. Argumentos n. ${ }^{\circ} 148$.

Macnaghten, Phil \& URrY, John, (1998): Contested Natures, London: SAGE Publications Ltd. in association with Theory, Culture \& Society, Nottingham Trend University.

MORMONT, M. (1987): «Rural nature and urban natures», en Sociologia Ruralis, $n .{ }^{\circ} 27$, vol. XXVII-1, pp. 3-20.

Pérez Vilariño, J (1993): «Organización y Cultura Forestal», en Actualidad Forestal de Galicia, Suplemento de la Revista El Campo, BBV, números 127-130, pp. 47-56. - (1998), «Construcción social del monte y desarrollo corporado del sector forestal», en Agricultura y Sociedad, n. ${ }^{\circ} 85$, pp. 15-42.

- (1992), «Desarrollo tecnológico y cultura forestal», en Actualidad Forestal de Galicia, suplemento de la Revista El Campo, n. ${ }^{\circ} 123-126$, enero-diciembre, pp. 24-31.

Precedo Ledo, A. (1994): Desenvolvemento Territorial e Planificación Comarcal, Santiago de Compostela: Gabinete de Planificación e Desenvolvemento Territorial, Consell. de Presidencia, Xunta de Galicia.

Ruiz Olabuenega, J.I. (1994): "Ocio y estilos de vida», en Juárez, M. (Dir.): V Informe Sociológico sobre la situación social en España. Sociedad para todos en el año 2000 , Madrid: Fundación FOESSA, tomo 2, 1881-2073. 


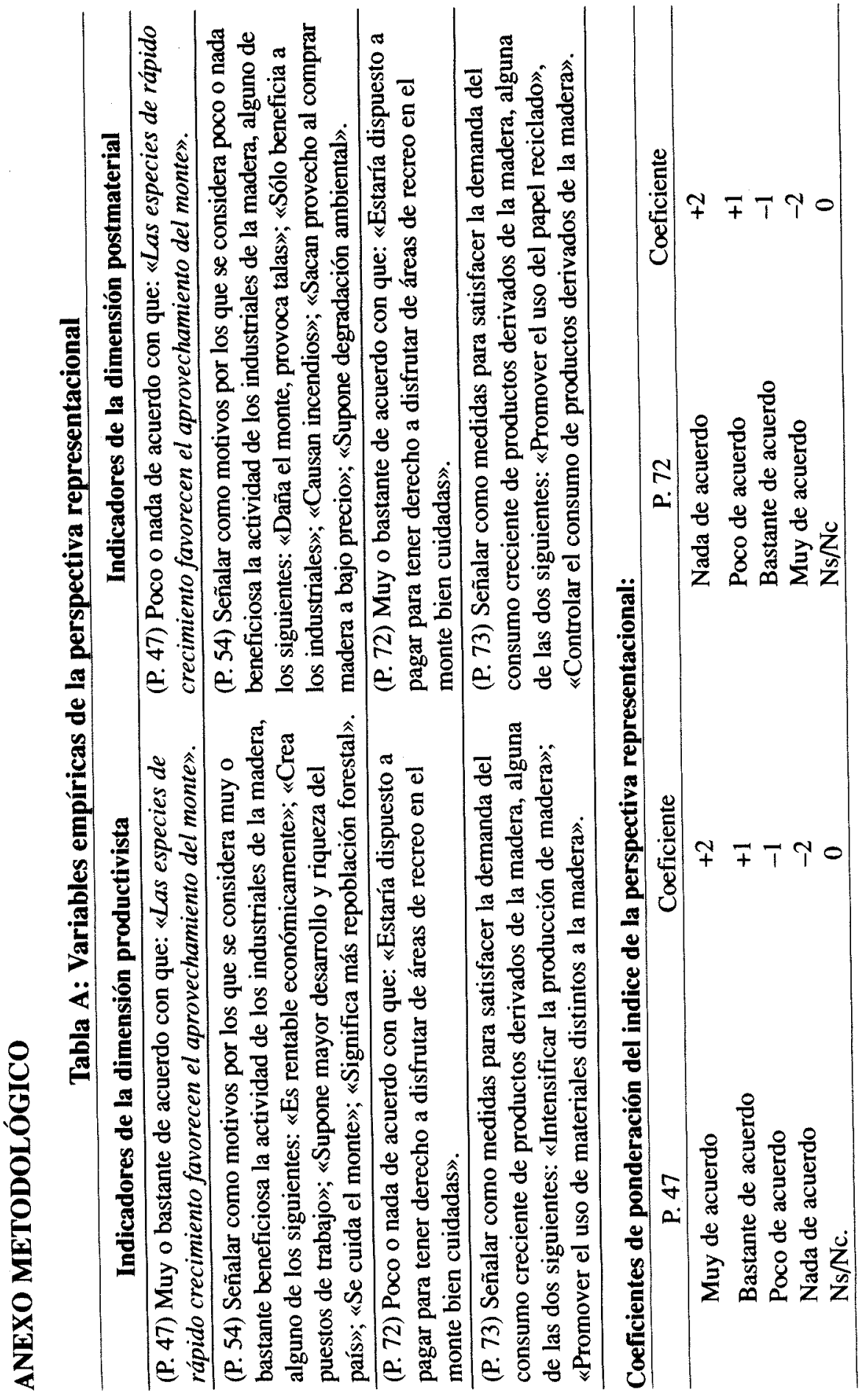


TIPOLOGIAS DE REPRESENTACIÓN SOCIAL DEL MONTE Y EL SECTOR FORESTAL...

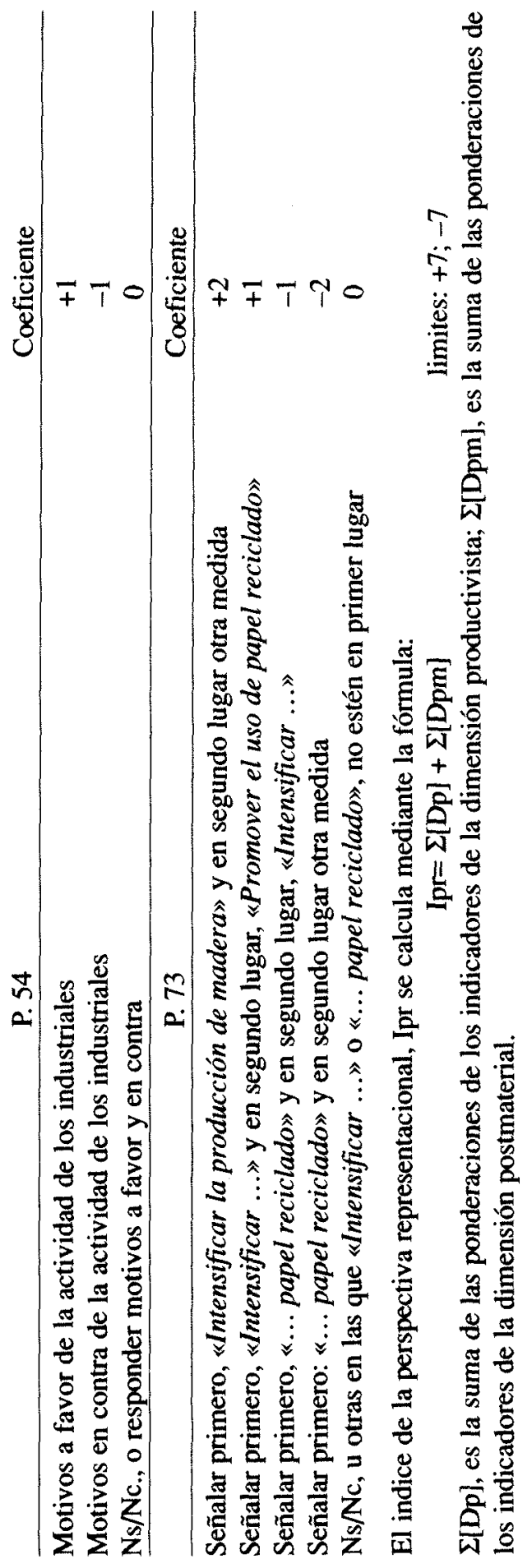


XESÚS A. LAGE PICOS

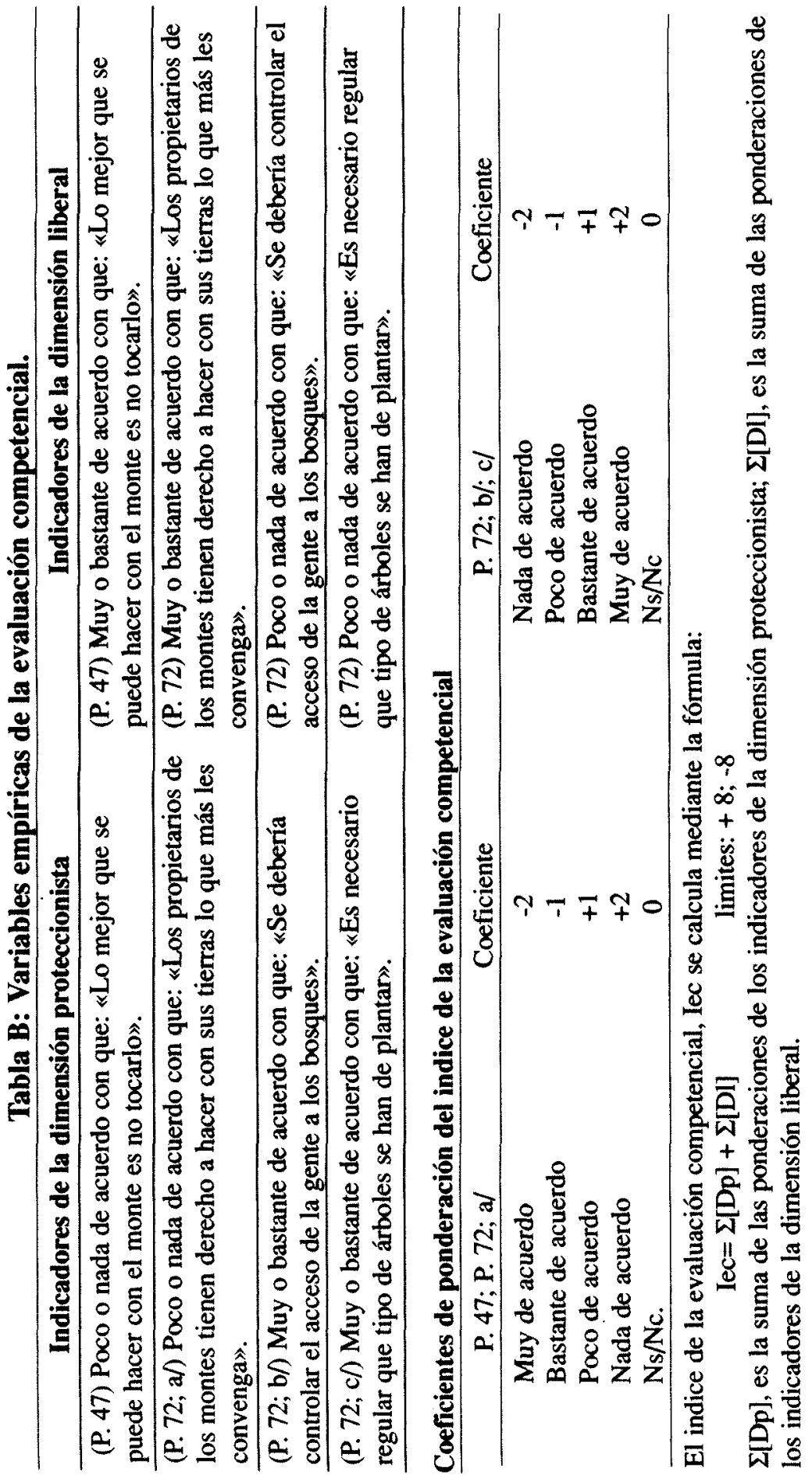

